\title{
Development and Validation of Knowledge, Attitude and Practice on Healthy Lifestyle Questionnaire (KAP-HLQ) for Malaysian Adolescents
}

\section{Hiew $\mathrm{CC}^{1}$, Chin $\mathrm{YS}^{* 1,2}$, Chan $\mathrm{YM}^{1,3}$ and Mohd Nasir MT ${ }^{1,2}$}

${ }^{1}$ Department of Nutrition and Dietetics, Faculty of Medicine and Health Sciences, Universiti Putra Malaysia, 43400 Serdang, Selangor, Malaysia

${ }^{2}$ Research Centre of Excellence, Nutrition and Non-communicable Diseases, Faculty of Medicine and Health Sciences, Universiti Putra Malaysia, 43400 Serdang, Selangor, Malaysia

${ }^{3}$ Institute of Gerontology, Faculty of Medicine and Health Sciences, Universiti Putra Malaysia, 43400 Serdang, Selangor, Malaysia

${ }^{*}$ Corresponding author: Chin YS, Department of Nutrition and Dietetics, Research Centre of Excellence, Nutrition and Non-communicable Diseases, Faculty of Medicine and Health Sciences, Universiti Putra Malaysia, 43400 Serdang, Selangor, Malaysia, E-mail: chinys@upm.edu.my

Citation: Hiew CC, Chin YS, Chan YM, Mohd Nasir MT (2015) Development and Validation of Knowledge, Attitude and Practice on Healthy Lifestyle Questionnaire (KAP-HLQ) for Malaysian Adolescents. J Nutr Health Sci 2(4): 407. doi: 10.15744/2393-9060.2.407

Received Date: October 13, 2015 Accepted Date: November 23, 2015 Published Date: November 24, 2015

\begin{abstract}
Objective: To develop and determine validity and reliability of the Knowledge, Attitude and Practice on Healthy Lifestyle Questionnaire (KAP-HLQ) among lower secondary adolescents.

Methods: The KAP-HLQ was developed with 56 knowledge, 62 attitude and 60 practice items on healthy lifestyle, and was completed by 647 Malaysian adolescents (13 to 15 years old) from 12 schools.

Results: Content validity and face validity of the KAP-HLQ were determined by three experts and 36 adolescents, respectively. Four attitude and six practice dimensions were identified through factor analysis in construct validity. Significant correlations between knowledge, attitude and practice showed adequate convergent validity. KAP-HLQ is reliable based on its internal consistency reliability (knowledge: $\alpha=0.654$, attitude: $\alpha=0.845$, practice: $\alpha=0.636$ ) and test-retest reliability (knowledge: $r=0.631$; attitude: $r=0.358$; practice: $\mathrm{r}=0.481$ ).

Conclusion: Evidence of validity and reliability of the KAP-HLQ (42 knowledge, 27 attitude, 28 practice items) have been obtained and can be used to assess KAP on healthy lifestyle among Malaysian adolescents.
\end{abstract}

Keywords: Malaysian adolescents; Healthy lifestyle; Knowledge; Attitude and Practice

\section{Introduction}

Knowledge is defined as a set of understandings, while attitude is a tendency or constant tendency towards certain objects, individuals or situations, and practice is an observable action towards the stimulus $[1,2]$. Knowledge, attitude and practice play main roles in the Knowledge-Attitude-Behaviour (KAB) model, which proposes that accumulated knowledge in a health aspect initiates changes in attitude, and results in gradual behaviour change [3]. This also means that people who are convinced when they obtain specific knowledge, will change their attitude and start practicing behaviour change.

A knowledge, attitude and practice survey is useful in evaluating the effectiveness of intervention programmes. In addition, it is able to assess a target group's current knowledge, attitude and practice on a specific health topic to identify their needs, problems and possible barriers before developing and implementing an intervention [4]. In recent healthcare studies worldwide such as in personal hygiene, nutrition, and diseases, knowledge, attitude and practice measures have been common, focusing on community or clinical settings in different populations [5-9]. However, there is lack of validated and reliable knowledge, attitude and practice instruments focusing on healthy lifestyle. As suggested by Parmenter and Wardle [10], an instrument might not be measuring the aspect that it is supposed to be and might not provide consistent and stable results if no validity and reliability tests were conducted. Moreover, existing instruments are usually developed for target populations in specific fields; therefore they might not be applicable to other studies [10]. 
This study aims to develop a Knowledge, Attitude and Practice Questionnaire on Healthy Lifestyle (KAP-HLQ) to evaluate the effectiveness of an intervention programme entitled "Healthy Lifestyle Program", which aims to educate adolescents on healthy lifestyle, focusing on healthy eating and active living. The intervention programme and KAP-HLQ were targeted towards lower secondary school adolescents (13 to 15 years old). In general, adolescence is a transition period between childhood and adulthood. This stage appears to be a crucial stage in the life cycle as adolescents could obtain a second chance to catch up with growth and development before adulthood [11]. Nevertheless, studies have found unhealthy eating habits such as meal skipping, snacking and energy dense food intake, as well as low physical activity level, prevalent among the population [12-15].

Adolescents are usually regarded as a group of healthy young people, but in fact, many of them suffer from chronic diseases [16]. In year 2012, approximately 1.3 million adolescents died worldwide, mostly due to preventable factors [16]. Studies suggested that healthy lifestyle, which was defined as people's preference towards combination of health-related behaviours based on life chances, is able to prevent lifestyle-related disorders and chronic diseases [17-19]. It is evident that recent interventions have focused on educating children and adolescents in obtaining an optimal body weight by energy balance through healthy diet and physical activities [20,21]. Therefore, there is a need to develop the KAP-HLQ to evaluate knowledge, attitude and practice on healthy lifestyle of Malaysian adolescents.

\section{Materials and Methods}

\section{Development of Knowledge, Attitude and Practice on Healthy Lifestyle Questionnaire (KAP-HLQ)}

The KAP-HLQ was developed to evaluate the effectiveness of the education module implemented in an intervention programme entitled "Healthy Lifestyle Program". The KAP-HLQ was developed mainly based on the Healthy Lifestyle Program education module, other related modules and guidelines [22-26]. The main focus of the education module is to convey messages on healthy lifestyle components, which consists of healthy eating and active lifestyle, to Malaysian adolescents. It highlights the importance of energy balance between healthy eating and active living to achieve an optimum body weight status. In order to practice healthy eating, healthy food choices and menu planning topics were included in the module. Moreover, topics in relation to warm-up and cool-down exercises, as well as the advantages of being physically active were included in the module to instil active lifestyle habits among adolescents.

Four schools were visited prior to developing the education module and KAP-HLQ. Brief interviews were carried out with the principals, Senior Assistants of Student Affairs, teachers, canteen caterers and adolescents to get an in-depth understanding of the adolescents' daily diets and physical activities, including their daily schedule and serving sizes in the dining hall and facilities available in schools. In order to suit the adolescents' needs and interests, the education module and teaching materials were tailored to their current regular meals and daily activities during and off school hours. Further, to enhance understanding of the items of the KAP-HLQ, the Malay language, which is the national language in the country, was used to develop the items. The initial set of KAP-HLQ consisted of three sections, namely knowledge, attitude and practice sections on healthy lifestyle.

\section{Development of knowledge section in KAP-HLQ}

Items developed in the knowledge section comprised healthy lifestyle elements (healthy eating and active lifestyle) with reference to the Malaysian Dietary Guidelines [25], which includes dietary and physical activity guidelines. For healthy eating, items were specified towards the Malaysian Food Guide Pyramid, food choices, food preparation methods, eating habits and concept of menu planning. As for active lifestyle, items were related to the Malaysian Physical Activity Pyramid, benefits of being physically active, as well as, warming up and cooling down activities needed for sports safety purposes. Additionally, items focusing on body weight status determination and energy balance were developed. As adolescents are undergoing puberty, items on growth and development were included to test on their knowledge on body changes. A total of 56 knowledge items were developed in the form of multiple choice questions, with four choices and only one correct answer. One point is given to a correct answer and a zero point is given to an incorrect answer. A higher total knowledge score indicates better knowledge of healthy lifestyle. Thus, the possible score range for the knowledge section is 0 to 56 points.

\section{Development of attitude section in KAP-HLQ}

Items developed in the attitude section of the KAP-HLQ focused on the attitudes of adolescents towards growth and development, healthy food and physical activity choices, food and physical activity functions, and dietary and physical activity recommendations, as were addressed in the intervention module of the Healthy Lifestyle Program. A total of 62 items were developed in the initial set of questionnaire. Each item was rated on a 5-point Likert scale, which includes "strongly disagree", "disagree", "between disagree and agree", "agree" and "strongly agree". Points are given in an ascending order, with one point given for the response of "strongly disagree" and five points given for the response of "strongly agree" for 40 positive items. Reverse scoring applies to 22 negatively structured items. The scores are added, and higher scores in the attitude section indicate more positive attitude on healthy lifestyle. This results in a possible minimum score of 62 points and a possible maximum score of 310 points for the attitude section. 


\section{Development of practice section in KAP-HLQ}

Items included in the practice section were about daily practices in selecting and consuming healthy food, planning dietary intake, appropriate meal frequencies, increasing physical activities and limiting sedentary activities, based on the intervention module implemented in the Healthy Lifestyle Program. A total of 60 practice items were developed in the initial set of KAP-HLQ. Each item was developed in a frequency scale. Choices of response given are "never", "seldom", "sometimes", "frequent" and "very frequent". One point is given for the lowest frequency in the scale and five points are given to the highest frequency in the scale for 29 positive items, whereas reverse scoring applies to 31 negatively structured items. Points are summed up and a higher score in this section indicates a healthier lifestyle practiced. For the practice section, the possible minimum score is 60 , while the possible maximum score is 300 .

\section{Study sample}

In this cross-sectional study, one group of respondents involved one school $(\mathrm{n}=36)$, which was randomly selected to determine the face validity of the KAP-HLQ, while another group of respondents was randomly selected using the probability proportionate to size sampling method to determine construct validity and internal consistency reliability of the KAP-HLQ. Twelve schools with 647 respondents were randomly selected in Malaysia. Subsequently, a subset of two schools with 118 respondents was randomly selected to determine the test-retest reliability of the KAP-HLQ.

For the sample size calculation, a ten respondents to one variable ratio was used for the calculation of respondents needed [27]. In other words, the number of respondents required for the study is equivalent to the number of items in the questionnaire multiply by ten. Since the attitude section had the most number of items (62 items), the sample size required was 620 respondents. To account for non-response, an extra $10 \%$ were added, resulting in a sample size of 682 respondents. All lower secondary adolescents (aged 13 to 15 years old) from the selected schools were invited to participate in the study. Adolescents with physical disabilities or chronic diseases were excluded from the study. The response rate of the study was $94.9 \%(n=647)$.

\section{Validity}

Three types of validities were determined for the KAP-HLQ. These include content validity, face validity and construct validity.

\section{Content validity}

Content validity refers to the extent to which the items on a measure assess the same content [28]. The content of the KAP-HLQ was determined by an expert panel, comprising three professionals in community nutrition, clinical nutrition and public health fields. Using a quantitative method, the experts rated each item in the KAP-HLQ as "essential", "useful", or "not necessary", in consideration of the appropriateness, ambiguity and accuracy of each item in the questionnaire. The content validity ratios (CVR) were then calculated using the Lawshe's formula [29] as shown below:

$C V R_{i}=\frac{n_{e}-\frac{N}{2}}{\frac{N}{2}}$

where,

$\mathrm{CVR}_{\mathrm{i}}=$ value for an item on the test

$\mathrm{n} \quad=$ number of experts indicating that an item is essential

$\mathrm{N}=$ total number of experts in the panel

Miller, Lovler and McIntire [30] stated that a CVR rating by five or less experts should be at least 0.99 when accepting or retaining a specific item.

\section{Face validity}

Face validity aims to determine the perception of respondents on the appropriateness of a test [30]. After determination of content validity by the expert panel, the KAP-HLQ was pretested among 36 adolescents in one of the schools to determine its face validity. Questionnaires were first distributed to the students, followed by standardized instructions given by trained researchers. Students were required to complete the questionnaire and were encouraged to raise up questions for doubtful or confusing items. These items were explained by trained researchers in a more understandable manner and highlighted to be adjusted thereafter.

\section{Construct validity}

Construct validity measures the underlying hypothetical concepts that the test was designed to measure [30]. After content validity and face validity, exploratory factor analysis was conducted for the attitude and practice sections of the KAP-HLQ using principal axis factoring to determine the underlying constructs for each section. Varimax rotation was used to present each factor in a more meaningful manner by theoretical reasoning. According to Field [31], in performing factor analysis, the variables must be able to be measured at an interval level. An example of such measure is the Likert scale [32]. Therefore, exploratory factor analyses for th- 
e knowledge section of the KAP-HLQ was excluded because this section is developed in a multiple choice form and do not meet the criteria as a variable measured at an interval level. As part of construct validity, convergent validity shows that other or similar constructs that theoretically should be related to the construct measured by the test in question are indeed related [30]. Convergent validity was assessed by correlating knowledge, attitude and practice on healthy lifestyle to determine the correlations of constructs to each other.

\section{Reliability}

After determination of validities, two types of reliabilities were determined in the study, including internal consistency reliability and test-retest reliability.

\section{Internal consistency reliability}

Internal consistency is one of the common methods used to determine the reliability of an instrument [33]. Internal consistency reliability aims to determine the similarity of items or set of items to each other [30].

First of all, item analysis was conducted to evaluate the performance of each test item [30]. For the knowledge section, item difficulty index (IDI) and discrimination index (DI) were determined. Meanwhile, item-to-total correlations (ITC) were determined for the attitude and practice sections. This is due to the structure of knowledge section being known facts, while the attitude and practice sections belong to abstract thinking and behavioural action structure. The IDI determines the proportion of respondents who are able to answer each item correctly [34]. Discrimination index compares the performance of those who obtained very high scores (upper group) with the performance of those who obtained very low scores (lower group) [30]. In determining the upper group and lower group, the $27.0 \%$ top scorers and low scorers were identified [35]. The acceptable range for the IDI was set between 0.3 and 0.9 [34], while the DI was categorized into excellent $(\geq 0.4)$, good (0.30-0.39), fair (0.11-0.29), poor (0.00-0.10) and majorly flawed $(<0.00)$ [36]. A good item should have both difficulty level and discrimination index in the appropriate range. On the other hand, ITC determines the contribution of each item towards overall test consistency and is able to discriminate top scorers and low scorers (alternative method for DI) [30]. An appropriate cut off for the ITC was set at 0.2 by Streiner and Norman [37].

Besides, the Kuder Richardson, et al. (KR-20) reliability coefficient was assessed to determine the internal consistency reliability of knowledge in KAP-HLQ, as knowledge items were constructed in multiple choice form. As for the attitude and practice sections of the KAP-HLQ with continuous data, the reliability coefficients (Cronbach's alpha) were determined. Drasgow [38] suggested that a reliability coefficient of 0.6 is appropriate for exploratory research.

\section{Test-retest reliability}

Test-retest reliability aims to determine the stability of an instrument in different situations and over a period of time [39]. In order to determine the test-retest reliability of the KAP-HLQ, a subset of two schools $(n=118)$ were randomly selected to complete the same set of questionnaire two weeks after the first data collection.

\section{Ethical approval and data collection}

Ethical approval was obtained from the Medical Research Ethics Committee, Faculty of Medicine and Health Sciences, Universiti Putra Malaysia. Prior to data collection, permission was granted by the Ministry of Education and State Departments of Education of the seven states to conduct the study in schools in these states.

During data collection, the selected students were gathered at the dining halls. Students were given information sheets and brief explanations regarding the research study. Informed consents were obtained from the respondents and their parents or guardians. The students were required to complete a set of questionnaire, which consisted of socio-demographic characteristic items (sex, age and ethnicity) and KAP-HLQ.

\section{Statistical analysis}

Data were analysed using the IBM SPSS Statistics for Windows Version 21.0 software [40]. Assumptions to conduct the exploratory factor analysis were met. Firstly, the Bartlett's test of sphericity is significant $(\mathrm{p}<0.0001)$. Secondly, the criteria for overall Measure of Sampling Adequacy (MSA) were met, having the value of 0.886 for attitude section and 0.777 for practice section of the instrument. Thirdly, the MSA for individual variables were examined and items that do not reach the minimum value of 0.5 were deleted [27]. Convergent validity and test-retest reliability were determined using Pearson product-moment correlations. Correlations were considered significant at a statistical level of $\mathrm{p}<0.05$. Besides, Cronbach's alpha and KR-20 were analysed for internal consistency reliability.

\section{Results}

\section{Socio-demographic characteristics}

Table 1 shows the socio-demographic background of the lower secondary school adolescents. This study involves a total of 647 adolescents with a mean age of $14.0 \pm 0.9$ years, which includes 215 (33.2\%) Form One students (13 years old), 222 (34.3\%) Form Two students (14 years old) and 210 (32.5\%) Form Three students (15 years old). Relatively more females (55.3\%) compared to males (44.7\%) participated in the study. Majority of the adolescents were Malay (85.7\%), followed by Sabah indigenous (10.4\%), Sarawak indigenous (1.4\%), students of other ethnic groups (1.1\%), Chinese (0.5\%) and Peninsular aborigines $(0.9 \%)$. 


\begin{tabular}{|c|c|c|c|c|}
\hline $\begin{array}{l}\text { Socio-demographic } \\
\text { characteristics }\end{array}$ & $\mathbf{n}$ & & Frequency n (\%) & Mean \pm S.D \\
\hline \multirow{6}{*}{ Region } & \multirow{6}{*}{647} & North Zone & $109(16.9)$ & \\
\hline & & East Coast & $162(25.0)$ & \\
\hline & & Central Zone & $63(9.7)$ & \\
\hline & & South Zone & $50(7.7)$ & \\
\hline & & Sabah & $74(11.5)$ & \\
\hline & & Sarawak & $189(29.2)$ & \\
\hline \multirow{2}{*}{ Area } & \multirow{2}{*}{647} & Urban & $272(42.0)$ & \\
\hline & & Rural & $375(55.3)$ & \\
\hline \multirow{2}{*}{ Sex } & \multirow{2}{*}{647} & Male & $289(44.7)$ & \\
\hline & & Female & $358(55.3)$ & \\
\hline \multirow{3}{*}{ Age } & \multirow{3}{*}{647} & Form 1 (13 years old) & $215(33.2)$ & \multirow{3}{*}{$14.0 \pm 0.9$} \\
\hline & & Form 2 (14 years old) & $222(34.3)$ & \\
\hline & & Form 3 (15 years old) & $210(32.5)$ & \\
\hline \multirow{6}{*}{ Ethnicity } & \multirow{6}{*}{647} & Malay & $555(85.7)$ & \\
\hline & & Chinese & $3(0.5)$ & \\
\hline & & Peninsular aborigines & $6(0.9)$ & \\
\hline & & Sabah indigenous & $67(10.4)$ & \\
\hline & & Sarawak indigenous & $9(1.4)$ & \\
\hline & & Others & $7(1.1)$ & \\
\hline
\end{tabular}

Table 1: Socio-demographic characteristics of adolescents

\section{Content validity}

For the knowledge section of the instrument, a total of 14 items did not meet the recommended CVR value $(<0.99)$ and were removed. Based on the comments provided by the expert panel, these items were found to be too technical for the adolescents, not conveyed in the intervention module, repetitive of similar concepts and controversial in literature reviews. For the attitude and practice sections of the KAP-HLQ, one item each was deleted because the messages were not conveyed in the intervention module. The process of content validity retained 42 knowledge items, 61 attitude items and 59 practice items.

\section{Face validity}

After content validity, the revised version of the KAP-HLQ was used to determine face validity. Most items in the KAP-HLQ were fully understood by the adolescents, except for terms such as "regularly" (secara berkala) and "low, moderate and high intensity activities" (aktiviti berintensiti rendah, sederhana dan tinggi). These items were defined in simpler phrases or via examples in the questionnaire to ease understanding of the items. For example, low, moderate and high intensity activities were given examples such as little energy needed, not too tiring, and rapid heartbeat, respectively. Time spent to complete the KAP-HLQ was approximately thirty minutes to one hour.

\section{Construct validity}

In the exploratory factor analysis, the scree plot revealed four dimensions in the attitude section and six dimensions in the practice section of the KAP-HLQ. Table 2 shows the results of factor analysis for the attitude and practice sections in the KAP-HLQ. In the final attitude model, four dimensions were identified with 27 items retained from the initial 62 items. The total variance accounted for the model was $33.81 \%$. Dimension 1 was accounted for $8.97 \%$ of variance explained and the six items grouped under this factor are related to the attitudes on the importance of functions of food and physical activity in leading a healthy lifestyle. Thus, Dimension 1 was named as "Attitude towards food and physical activity functions". A total of $8.86 \%$ variance was explained by Dimension 2, which consisted of eight items. These items assess the choices of adolescents towards healthy food and physical activity. Dimension 2 was named as "Attitude towards food and physical activity choices". Dimension 3 was accounted for $8.49 \%$ variance explained. The eight items classified in this dimension are regarding the adolescents' willingness and confidence to practice healthy eating and active lifestyle for optimum growth and development during the adolescence stage and towards adulthood. Based on the items grouped in Dimension 3, it was named as "Attitude towards growth and development". Dimension 4 accounted for the least percentage of variance explained, which was 7.50\%. Five items were identified in this dimension to assess the determination of meeting the recommended dietary and physical activity guidelines based on the Malaysian Dietary Guidelines [25]. Therefore, Dimension 4 was named as "Attitude towards dietary and physical activity recommendations". Although crossloadings were demonstrated in six attitude items, the items were judged to be included in suitable dimension based on theoretical reasons. 


\begin{tabular}{|c|c|c|c|c|c|c|c|}
\hline Section/ Dimension & $\begin{array}{l}\text { Number of } \\
\text { items }\end{array}$ & Eigen value & $\begin{array}{l}\text { Percentage } \\
\text { of variance } \\
\text { explained }\end{array}$ & $\begin{array}{l}\text { Range of factor } \\
\text { loadings }\end{array}$ & $\begin{array}{l}\text { Reliability } \\
\text { coefficient } \\
\text { (Cronbach's } \\
\text { alpha) }\end{array}$ & $\begin{array}{l}\text { Test-retest } \\
\text { reliability }\end{array}$ & $\begin{array}{l}\text { Test-retest } \\
\text { reliability }\end{array}$ \\
\hline Knowledge & -- & -- & -- & -- & 0.654 & $0.631^{\star *}$ & -- \\
\hline Attitude & 27 & -- & 33.81 & -- & 0.845 & $0.358^{* *}$ & -- \\
\hline $\begin{array}{l}\text { Dimension 1: Attitude towards } \\
\text { food and physical activity functions }\end{array}$ & 6 & 2.421 & 8.97 & $0.405 \sim 0.670$ & 0.797 & 0.069 & $0.491 \sim 0.628$ \\
\hline $\begin{array}{l}\text { Dimension 2: Attitude towards } \\
\text { food and physical activity choices }\end{array}$ & 8 & 2.391 & 8.86 & $0.355 \sim 0.641$ & 0.749 & $0.549^{* *}$ & $0.336 \sim 0.524$ \\
\hline $\begin{array}{l}\text { Dimension 3: Attitude towards } \\
\text { growth and development }\end{array}$ & 8 & 2.292 & 8.49 & $0.315 \sim 0.603$ & 0.759 & $0.259^{* *}$ & $0.310 \sim 0.573$ \\
\hline $\begin{array}{l}\text { Dimension 4: Attitude towards } \\
\text { dietary and physical activity rec- } \\
\text { ommendations }\end{array}$ & 5 & 2.026 & 7.50 & $0.302 \sim 0.546$ & 0.643 & 0.176 & $0.314 \sim 0.485$ \\
\hline Practice & 28 & -- & 37.84 & -- & 0.636 & $0.481^{* *}$ & -- \\
\hline Dimension 1: Meal frequency & 4 & 2.141 & 7.65 & $0.453 \sim 0.787$ & 0.750 & $0.299^{* *}$ & $0.450 \sim 0.648$ \\
\hline $\begin{array}{l}\text { Dimension 2: Daily intake of food } \\
\text { groups }\end{array}$ & 5 & 1.858 & 6.64 & $0.318 \sim 0.744$ & 0.684 & $0.232^{*}$ & $0.253 \sim 0.571$ \\
\hline $\begin{array}{l}\text { Dimension 3: Energy dense food } \\
\text { intake }\end{array}$ & 5 & 1.857 & 6.63 & $0.535 \sim 0.682$ & 0.734 & $0.353^{* *}$ & $0.488 \sim 0.577$ \\
\hline $\begin{array}{l}\text { Dimension 4: Food selection and } \\
\text { menu planning }\end{array}$ & 4 & 1.655 & 5.91 & $0.463 \sim 0.744$ & 0.674 & $0.353^{* *}$ & $0.363 \sim 0.558$ \\
\hline $\begin{array}{l}\text { Dimension 5: Physical activity } \\
\text { practices }\end{array}$ & 4 & 1.614 & 5.76 & $0.331 \sim 0.641$ & 0.656 & $0.386^{* *}$ & $0.253 \sim 0.504$ \\
\hline Dimension 6: Sedentary activities & 6 & 1.471 & 5.25 & $0.455 \sim 0.606$ & 0.649 & $0.386^{* *}$ & $0.362 \sim 0.502$ \\
\hline
\end{tabular}

${ }^{*} \mathrm{p}<0.05 ;{ }^{* *} \mathrm{p}<0.01$

Table 2: Summary results of factor analysis and reliability for knowledge, attitude and practice towards healthy lifestyle

In the final practice model, 28 items were retained from the initial 60 items. There were six dimensions revealed in this section, having four dimensions related to food and nutrition and another two dimensions related to physical activity. Dimension 1 was accounted for $7.65 \%$ of variance explained. Five items located in the first dimension aimed towards main meal skipping and dieting practice for the past seven days. Hence, Dimension 1 was named as "Meal frequency". Dimension 2 contributed to 6.64\% variance explained, with five items identified in the dimension. This dimension assesses the five food group consumption for the past week. Dimension 2 was termed as "Daily intake of food groups". Dimension 3 was accounted for $6.63 \%$ of variance explained, being represented by four items in relation of energy dense food and empty calorie food intake. According to the items in the dimension, Dimension 3 was termed as "Energy dense food intake". It was followed by Dimension 4 with $5.91 \%$ variance explained. Four items were identified in this dimension to represent the frequency of healthy food selection and planning healthy menu. Dimension 4 was named as "Food selection and menu planning". Dimension 5 was accounted for 5.76\% of variance explained, with six items in regards of the involvement of low, moderate and high intensity physical activities. In summarizing the items in the dimension, Dimension 5 was named as "Physical activity practices". Last but not least, Dimension 6 accounted for the least variance explained (5.25\%). Four items related to sedentary activities such as television and computer usage were classified in this dimension. Dimension 6 was termed as "Sedentary activities". Cross loadings were presented in two practice items, but were judged to retain at appropriate dimensions.

After conducting exploratory factor analysis, convergent validity of the KAP-HLQ was determined. Convergent validity as determined by correlating knowledge, attitude and practice on healthy lifestyle sections among adolescents showed significant and positive associations. The correlations between knowledge and attitude $(\mathrm{r}=0.260, \mathrm{p}=0.0001)$, knowledge and practice ( $\mathrm{r}=0.201$, $\mathrm{p}=0.0001)$, as well as attitude and practice $(\mathrm{r}=0.517, \mathrm{p}=0.0001)$ on healthy lifestyle indicate that adolescents with good knowledge on healthy lifestyle components have positive attitude and practice healthy lifestyles.

\section{Internal consistency reliability}

Item analysis was determined before analysing the reliability coefficient of the KAP-HLQ. Out of 42 knowledge items, 34 items met the acceptable range for IDI (0.30-0.90). For DI, most knowledge items were classified in the excellent ( $\geq 0.40)(14$ items) and good category (0.30-0.39) (14 items), six knowledge items were categorized as fair (0.11-0.29), and eight items were grouped in the poor category (0.00-0.10) (Hopkins, 1998). No items were majorly flawed $(<0.00)$ [36]. As presented in Table 2, the item-tototal correlations (ITC) for each item in the attitude and practice sections was above the recommended cut off (0.20) [37]. The performance of each item in the KAP-HLQ was relatively good. Hence, no items were removed in the process of item analysis. 
Table 2 shows the reliability results for the knowledge, attitude and practice sections of the KAP-HLQ. The KR-20 value for the knowledge of KAP-HLQ is 0.656. In the attitude section, the Cronbach's alpha for the model is 0.845, while in the practice section of the KAP-HLQ, the Cronbach's alpha for the model is 0.636 . All dimensions in the attitude and practice sections of the KAPHLQ have fulfilled the minimum internal consistency reliability of at least 0.6 for such exploratory research [38].

Table 3 shows the inter-correlation between dimensions of attitude section in KAP-HLQ. It has been suggested that the correlations should be high, but not too high [41]. Dancey and Reidy [42] also suggested that a correlation coefficient of 0.7 or above is considered as a strong association. In the attitude section of KAP-HLQ, all dimensions are significantly correlated with each other, with $\mathrm{r}$-values that range from low to moderate (0.116 0.629). For the practice section, eight out of 15 correlations were significant, with $r$-values of the correlations ranging from low to moderate $(0.088 \sim 0.403)$. This indicates that the items are measuring the same aspect at different dimensions.

\begin{tabular}{|c|c|c|c|c|c|c|c|c|}
\hline \multirow[b]{2}{*}{ Dimension } & \multicolumn{3}{|c|}{ Attitude Section of KAP-HLQ } & \multicolumn{5}{|c|}{ Practice Section of KAP-HLQ } \\
\hline & $\begin{array}{l}\text { Dimension } \\
\text { 1: Attitude } \\
\text { towards } \\
\text { food and } \\
\text { physical } \\
\text { activity } \\
\text { functions }\end{array}$ & $\begin{array}{l}\text { Dimension } \\
\text { 2: Attitude } \\
\text { towards } \\
\text { food and } \\
\text { physical } \\
\text { activity } \\
\text { choices }\end{array}$ & $\begin{array}{l}\text { Dimension } \\
\text { 3: Attitude } \\
\text { towards } \\
\text { growth and } \\
\text { develop- } \\
\text { ment }\end{array}$ & $\begin{array}{l}\text { Dimension } \\
\text { 1: Meal } \\
\text { frequency }\end{array}$ & $\begin{array}{l}\text { Dimension } \\
\text { 2: Daily in- } \\
\text { take of food } \\
\text { groups }\end{array}$ & $\begin{array}{l}\text { Dimension } \\
\text { 3: Energy } \\
\text { dense food } \\
\text { intake }\end{array}$ & $\begin{array}{l}\text { Dimension } \\
\text { 4: Food } \\
\text { selection } \\
\text { and menu } \\
\text { planning }\end{array}$ & $\begin{array}{l}\text { Dimension } \\
\text { 5: Physical } \\
\text { activity } \\
\text { practices }\end{array}$ \\
\hline \multicolumn{9}{|l|}{ Attitude of KAP-HLQ } \\
\hline $\begin{array}{l}\text { Dimension 2: Attitude towards } \\
\text { food and physical activity } \\
\text { choices }\end{array}$ & $0.156^{* *}$ & -- & -- & -- & -- & -- & -- & -- \\
\hline $\begin{array}{l}\text { Dimension 3: Attitude towards } \\
\text { growth and development }\end{array}$ & $0.629^{* *}$ & $0.116^{* *}$ & -- & -- & -- & -- & -- & -- \\
\hline $\begin{array}{l}\text { Dimension } 4 \text { : Attitude towards } \\
\text { dietary and physical activity } \\
\text { recommendations }\end{array}$ & $0.470^{* *}$ & $0.332^{\star *}$ & $0.439^{* *}$ & -- & -- & -- & -- & -- \\
\hline \multicolumn{9}{|l|}{ Practice of KAP-HLQ } \\
\hline $\begin{array}{l}\text { Dimension 2: Daily intake of } \\
\text { food groups }\end{array}$ & -- & -- & -- & 0.061 & -- & -- & -- & -- \\
\hline $\begin{array}{l}\text { Dimension 3: Energy dense } \\
\text { food intake }\end{array}$ & -- & -- & -- & $0.403^{\star *}$ & $-0.102^{* *}$ & -- & -- & -- \\
\hline $\begin{array}{l}\text { Dimension } 4 \text { : Food selection } \\
\text { and menu planning }\end{array}$ & -- & -- & -- & -0.069 & $0.144^{\star *}$ & 0.020 & -- & -- \\
\hline $\begin{array}{l}\text { Dimension 5: Physical activity } \\
\text { practices }\end{array}$ & -- & -- & -- & $0.234^{\star *}$ & $0.088^{\star}$ & -0.071 & $0.317^{\star *}$ & -- \\
\hline $\begin{array}{l}\text { Dimension 6: Sedentary } \\
\text { activities }\end{array}$ & -- & -- & -- & 0.015 & 0.026 & $0.148^{\star *}$ & 0.057 & $-0.124^{* *}$ \\
\hline
\end{tabular}

${ }^{*} \mathrm{p}<0.05 ;{ }^{* *} \mathrm{p}<0.01$

Table 3: Inter-correlations between dimensions of attitude and practice on healthy lifestyle

\section{Test-retest reliability}

Table 2 presents the test-retest reliability for the KAP-HLQ. The test-retest reliability for knowledge $(\mathrm{r}=0.631, \mathrm{p}=0.0001)$, attitude $(\mathrm{r}=0.358, \mathrm{p}=0.0001)$ and practice $(\mathrm{r}=0.481, \mathrm{p}=0.0001)$ sections of the KAP-HLQ showed moderate correlations. From the scores generated from four attitude dimensions, dimensions on "Attitude towards food and physical activity choices" and "Attitude towards growth and development" were found to be stable after a period of time. Similar stability of scores were found in all six practice dimensions.

\section{Final model of KAP-HLQ}

The final model of the knowledge section of KAP-HLQ has a total of 42 items. This works out to a possible minimum score of 0 points, and a possible maximum score of 42 points. As items of knowledge on healthy lifestyle measures known facts and not abstract variables, it should not be further defined into general factors [43]. Therefore, knowledge section is reported by total score, with higher score indicating better knowledge on healthy lifestyle.

A total of 27 items were retained in the attitude section of KAP-HLQ. Attitude on healthy lifestyle can be assessed by total score and dimension score. This is further supported by the high Cronbach's alpha values of each dimension and total attitude score. The possible minimum total score of this section is 27 points and the possible maximum total score is 135 points. When scoring is concerned, reverse scoring applies to nine negatively developed statements. Negatively structured items were regarding preference of energy dense snacks and fried foods, selecting of high fat or low fat food preparation methods, choosing high sugar or low su- 
gar beverages, preference of eating or performing physical activities, preference of sedentary activities (playing computer games; chatting) or outdoor activities, preference of less movements or low intensity activities, and delayed awareness of healthy lifestyle. A higher score in each dimension and total score in the attitude section indicate a more positive attitude of the adolescent towards the measured variables.

For the practice section of the KAP-HLQ, 28 items that fit in the instrument were retained. Practice on healthy lifestyle can be assessed by total practice score and by dimension score. The high Cronbach's alpha values for total practice score and each dimension have assured the ability of the scoring method. The possible minimum total practice score is 28 and the possible maximum total practice score is 140 points. Reverse scoring applies to 16 negatively constructed statements. These items are related to daily intakes of food groups, food choices, main meal and snacks planning, choices made while ordering food and beverages while eating out, performing moderate and high intensity activities, and sedentary activities during weekdays and weekends. Higher scores in each dimension and total score of the section indicate healthier practice of the adolescents' lifestyles.

\section{Discussion}

The KAP-HLQ is able to serve as an important assessment tool as it has been developed and tailored to the adolescents' needs and daily lifestyles. In addition, it has been tested for its validity and reliability. These include content validity by the expert panel, face validity by adolescents of similar characteristics as the target group, construct validity using exploratory factor analysis, convergent validity by correlating knowledge, attitude and practice on healthy lifestyle, internal consistency reliability and testretest reliability.

For content validity, consensus was met in reviewing the KAP-HLQ based on the contents of the intervention module. It is important to match the content domains with the module as it is meant to evaluate the effectiveness of the Healthy Lifestyle Program. Similar procedures were applied by other researchers [44]. The determination of content validity supports the recommendation by DeVon, et al. [45] that content validity should refer to the process stated by Lynn [46] or Lawshe [29], with at least three experts for adequate inter-rater agreement $[28,46]$. In the determination of face validity, comprehensibility of items by the target group is important, especially for instruments developed for a specific population. Majority of the items developed in the KAP-HLQ were well understood by the adolescents, with an exception on certain terminologies, which were revised to serve the purpose. It may be attributed to the nature of the KAP-HLQ which was developed based on the adolescents' dietary and activity routines as well as the use of Malay language which represents the adolescents' education language medium. This echoes the importance of face validity in determining the appropriateness of instrument for a specific target group as highlighted in a questionnaire developed for American Indian children [47].

For construct validity of the KAP-HLQ through exploratory factor analysis, six attitude items and three practice items presented lower factor loadings but within the recommended range (0.30-0.40) [27]. Items included were theoretically important to explain its construct. It was also suggested that researchers should consider removing items with cross loadings [27]. A total of six items in the attitude section and two items in the practice section of the KAP-HLQ have demonstrated cross loadings. However, taking theoretical reasoning into consideration, these items were retained. Lowenthal, et al. [48] suggested that statistical analysis is merely one method to identify items to be retained in the model, and researchers should judge that the items retained and grouped together do provide appropriate meanings. The attitude and practice dimensions were named based on the shared concept by items grouped in its dimension. These main concerns on nutrition and physical activities have been studied in focus group discussions conducted among adolescents [49,50]. Adolescents expressed their cravings and preference of taste when selecting food to be consumed [49]. For example, they tend to choose energy dense food because it tastes better than healthy food. In addition, they were not willing to comply with recommendations or guidelines because they feel that they were too young to worry about health problems at this stage. Furthermore, adolescents were more interested in indoor activities and they feel tired to exercise [50].

In convergent validity, the positive significant correlations among knowledge, attitude and practice on healthy lifestyle indicate that adolescents who have good knowledge on healthy lifestyle have positive attitudes and do practice healthy lifestyles. The significant correlations support the definition of convergent validity, suggesting that variables theoretically related should be related to each other. Moreover, the associations among knowledge, attitude and practice on healthy lifestyle assessed using KAP-HLQ are relatively similar with the Malaysian study (HELIC study) which involved primary school children [51]. However, the results were contradictory with a study conducted among sixth grade adolescents in the United States, where there was no correlation found between nutrition knowledge and eating behaviour [52]. Despite this, significant correlation was found between nutrition knowledge and eating behaviour among seventh and eighth grade girls [52]. On the other hand, we observed low to moderate correlations among knowledge, attitude and practice on healthy lifestyle probably due to the presence of other variables that might affect the association among knowledge, attitude and practice towards healthy lifestyle, such as situational and environmental factors [53]. Moreover, the readiness to change in nutrition and physical activity plays an important role in the correlations of knowledge, attitude and practice on healthy lifestyle [54]. For example, a person who has knowledge but not prepared to change his lifestyle, will not correspond to positive attitude towards healthy lifestyle and practice.

For item analysis, eight knowledge items in the KAP-HLQ did not meet the recommended range for IDI [34]. However, these items were retained in consideration of their relevance and importance in reflecting knowledge on healthy lifestyle. This situation is similar to the newly developed Nutrition Knowledge, Attitude and Practice Questionnaire in Persons with Disabilities (KAPnOKU), whereby several items with low difficulty index were retained because these items could represent specific topics in the n- 
utrition education programme [55]. Besides, no knowledge items in the KAP-HLQ were classified as majorly flawed (<0.00), thus all items were retained in the process. Since all items in the attitude and practice sections of the KAP-HLQ have fulfilled the mentioned criteria, no items were removed. For internal consistency reliability, knowledge, attitude and practice sections, as well as all dimensions in the attitude and practice sections of the KAP-HLQ have obtained reliability coefficients of more than 0.6 [38]. The reliability coefficients comply with the recommendation for exploratory research. The reliability coefficients of existing knowledge, attitude and practice instruments related to nutrition and physical activity ranged from as low as 0.360 to as high as $0.760[51,56]$. Therefore, the reliability coefficients for the KAP-HLQ $(0.656 \sim 0.845)$ are towards the higher end when compared to other existing knowledge, attitude and practice instruments in the related field [51,57]. In addition, the inter-correlation between dimensions of attitude and practice in the KAP-HLQ showed that each dimension was measuring different constructs within a same aspect. Although several inter-correlations between practice dimensions were not significant, the item analysis and reliability coefficient showed good internal consistency of the items.

The test-retest reliability of the KAP-HLQ was determined by correlating between the first and second administrations of questionnaire in a two-week interval. This duration was suggested appropriate by Waltz, Strickland and Lenz [58], as it is sufficient not to remember the responses, but not too long to have their knowledge, attitude and practice on healthy lifestyle to change [45]. Most correlations of the dimensions in the KAP-HLQ were significant, ranging from low to moderate (0.23 0.63). This is consistent with the Pathways study conducted among a group of fourth grade American Indian children [47], whereby the correlations ranged from 0.22 to 0.65 . The test-retest reliability correlations of "Attitude towards food and physical activity functions" and "Attitude towards dietary and physical activity recommendations" dimensions were not significant. This is most probably because the adolescents were unsure of their responses towards food and physical activity functions and recommendations; hence unable to provide the same response in the questionnaire administered at different times. A focus group discussion in exploring lifestyles of adolescents reported that adolescents are able to identify the benefits and functions of food and physical activity, but refused to comply with the recommendations as they were not worried about risk of diseases later in life [49]. Besides, peer influence plays an important role in affecting the adolescents' mindset, whereby adolescents act differently in the presence of peers [59].

There are some limitations and recommendations of the study that should be addressed. Due to the comprehensiveness of the intervention module, a large number of items were included in the KAP-HLQ. This may be a challenge to the adolescents' patience. However, for the final model of the KAP-HLQ, adolescents should take less than 30 minutes to complete the questionnaire. Future research can conduct principal component analysis to reduce the number of items in the KAP-HLQ. Besides, this instrument was validated among Malaysian adolescents, and may not be suitable to assess other populations and in other countries, due to different environment and exposure of the target group. Researchers are recommended to validate and modify the KAP-HLQ among other populations, and use the instrument as baseline information for future healthy lifestyle interventions for them.

\section{Conclusion}

Evidence of validity of the newly developed KAP-HLQ has been obtained. This instrument can serve as an important tool to evaluate knowledge, attitude and practice on healthy lifestyle among Malaysian adolescents.

\section{Acknowledgements}

This study was sponsored by Nestle Products Pte Ltd under Nestle Healthy Kids project. The authors would like to extend sincere appreciation towards cooperation among all stakeholders (Nestle Products Pte Ltd, Ministry of Education of Malaysia and Universiti Putra Malaysia).

\section{References}

1. Baranowski T, Cullen KW, Nicklas T, Thompson D, Baranowski J (2003) Are Current Health Behavioral Change Models Helpful in Guiding Prevention of Weight Gain Efforts? Obes Res 11: 23S-43S.

2. Mucchielli R (1970) Introduction to structural psychology. Funk \& Wagnalls, New York.

3. Gumucio S, Merica M, Luhmann N, Fauvel G, Zompi S, et al. (2011) The KAP Survey Model. Accessed on 20 March 2013.

4. World Health Organization (2008) A guide to developing knowledge, attitude and practice surveys. Accessed on 18 June 2012.

5. Abiola AO, Nwogu EE, Ibrahim MT, Hassan R (2015) Effect of Health Education on Knowledge, Attitude and Practices of Personal Hygiene among Secondary School Students in Rural Sokoto, North West, Nigeria. Nig Q J Hosp Med 22: 181-90.

6. Abd Elaziz KM, Bakr IM (2015) Assessment of knowledge, attitude and practice of hand washing among health care workers in Ain Shams University hospitals in Cairo. J Prev Med Hyg 50: 19-25.

7. Gautam A, Bhatta DN, Aryal UR (2015) Diabetes related health knowledge, attitude and practice among diabetic patients in Nepal. BMC Endocr Disord 15: 25. 8. Ho TS, Huang MC, Wang SM, Hsu HC, Liu CC (2013) Knowledge, attitude, and practice of dengue disease among healthcare professionals in southern Taiwan. J Formosan Medic Assoc 112: 18-23.

9. Wall DE, Least C, Gromis J, Lohse B (2012) Nutrition Education Intervention Improves Vegetable-Related Attitude, Self-Efficacy, Preference, and Knowledge of Fourth-Grade Students. J Sch Health 82: 37-43.

10. Parmenter K, Wardle J (2000) Evaluation and Design of Nutrition Knowledge Measures. J Nutri Edu 32: 269-77.

11. World Health Organization (2012) Adolescent health, Assessed on 24 January 2012.

12. Boon TY, Sedek R, Kasim ZM (2012) Association between snacking patterns, energy and nutrient intakes, and body mass index among school adolescents in Kuala Lumpur. Am J Food and Nutri 2: 69-77.

13. Fitzgerald A, Heary C, Kelly C, Nixon E, Shevlin M (2013) Self-efficacy for healthy eating and peer support for unhealthy eating are associated with adolescents' food intake patterns. Appetite 63: 48-58. 
14. Meehan M, Yeh MC, Spark A (2008) Impact of exposure to local food sources and food preparation skills on nutritional attitudes and food choices among urban minority youth. J Hunger Environmen Nutri 3: 456-71.

15. Nurul-Fadhilah A, Teo PS, Huybrechts I, Foo LH (2013) Infrequent breakfast consumption is associated with higher body adiposity and abdominal obesity in Malaysian school-aged adolescents. PLoS One 8: e59297.

16. World Health Organization (2012) Young people: health risks and solutions. Assessed on 24 January 2012.

17. Cockerham WC (2000) Handbook of Medical Sociology (5th edn). Prentice-Hall, Upper Saddle River, NJ, United States.

18. Pronk NP, Anderson LH, Crain AL, Martinson BC, O’Connor PJ, et al. (2004) Meeting recommendations for multiple healthy lifestyle factors. Am J Prev Med 27: $25-33$

19. von Bothmer MIK, Fridlund B (2005) Gender differences in health habits and in motivation for a healthy lifestyle among Swedish university students. Nurs Health Scis 7: 107-18.

20. Chomitz VR, McGowan RJ, Wendel JM, Williams SA, Cabral HJ, et al. (2010) Healthy Living Cambridge Kids: A Community-based Participatory Effort to Promote Healthy Weight and Fitness. Obesity 18: S45-53.

21. Tse MM, Yuen DT (2009) Effects of providing a nutrition education program for teenagers: dietary and physical activity patterns. Nurs Health Sci 11: $160-5$.

22. Kumpulan Kerja Kebangsaan (2003) Sihat Sepanjang Hayat. Bahagian Pendidikan Kesihatan Kementerian Kesihatan Malaysia, Malaysia.

23. National Working Group on Healthy Eating (1996) Healthy Eating. The Healthy Education Division, Ministry of Healthy Malaysia, Malaysia.

24. National Coordinating Committee on Food and Nutrition (2005) Recommended Nutrient Intakes for Malaysia. Ministry of Health Malaysia, Putrajaya, Malaysia.

25. National Coordinating Committee on Food and Nutrition (2010) Malaysian Dietary Guidelines. Ministry of Health Malaysia, Putrajaya, Malaysia.

26. Neumark-Sztainer D, Story M, Hannan PJ, Rex J (2003) New Moves: A school-based obesity prevention program for adolescent girls. Prev Med 37: 41-51.

27. Hair JF (Jr.), Black WC, Babin BJ, Anderson RE (2009) Multivariate Data Analysis (7th edn). Pearson Prentice Hall, Upper Saddle River, NJ, United States.

28. Rubio DM, Berg-Weger M, Tebb SS, Lee ES, Rauch S (2003) Objectifying content validity: Conducting a content validity study in social work research. Social Work Rese 27: 94-104.

29. Lawshe CH (1975) A quantitative approach to content validity. Personnel Psychology 28: 563-75.

30. Miller LA, Lovler RL (2013) Foundations of Psychological Testing: A practical approach. SAGE Publications, Inc, Thousand Oaks, CA, United States.

31. Field A (2009) Discovering Statistics using SPSS. Sage, London.

32. Rattray JC, Jones MC (2007) Essential elements of questionnaire design and development. J Clin Nurs 16: $234-43$.

33. Windsor R, Clark N, Boyd N, Goodman RM (2004) Evaluation of health promotion, health education, and disease prevention programs (3rd edn). McGrawHill, Boston, MA, United States.

34. Oosterhof A (2001) Classroom Applications of Educational Measurement (3rd edn). Merrill, Upper Saddle River, NJ, United States.

35. Kelley TL (1939) The selection of upper and lower groups for the validation of test items. J Edu Psychol 30: 17-24.

36. Hopkins KD (1998) Educational and psychological measurement and evaluation (8th edn). Allyn \& Bacon, Boston, MA, United States.

37. Streiner DL, Norman GR (2003) Health measurement scales: a practical guide to their development and use (3rd ed). Oxford University Press, New York.

38. Drasgow F (1984) Scrutinizing Psychological Tests: Measurement Equivalence and Equivalent Relations with External Variables Are the Central Issues. Psycholo Bulle 95: 134-5.

39. Reynolds CR, Livingston RB (2012) Mastering Modern Psychological Testing: Theory \& Methods. Pearson Education, Inc, Upper Saddle River, NJ, United States.

40. IBM SPSS Statistics for Windows, Version 21.0. IBM Corp, Armonk, NY, United States.

41. Streiner DL, Norman GR (2008) Health measurement scales: a practical guide to their development and use (4th edn). Oxford University Press, New York, United States.

42. Dancey CP, Reidy J (2002) Statistics without Maths for Psychology (2nd edn). Prentice-Hall, London, United Kingdom.

43. Bryman A, Cramer D (2005) Quantitative Data Analysis with SPSS 12 and 13: A Guide for Social Scientists. Routledge, East Sussex, United Kingdom.

44. Yamada J, Stevens B, Sidani S, Watt-Watson J, de Silva N (2010) Content Validity of a Process Evaluation Checklist to Measure Intervention Implementation Fidelity of the EPIC Intervention. Worldviews on Evidence-Based Nursing 7: 158-64.

45. DeVon HA, Block ME, Moyle-Wright P, Ernst DM, Hayden SM, et al. (2007) A psychometric toolbox for testing validity and reliability. J Nurs Scholarsh 39: 155-64.

46. Lynn MR (1986) Determination and quantification of content validity. Nurs Res 35: 382-5.

47. Stevens J, Cornell, CE, Story M, French SA, Levin S, et al. (1999) Development of a questionnaire to assess knowledge, attitudes, and behaviors in American Indian children. Am J Clin Nutr 69: 773S-81S.

48. Lowenthal KM (2001) An introduction to psychological tests and scales (2nd edn). Psychology Press, Philadelphia, United States.

49. Neumark-Sztainer D, Story M, Perry C, Casey MA (1999) Factors influencing food choices of adolescents: Findings from focus-group discussions with adolescents. J Am Diet Assoc 99: 929-37.

50. O’Dea JA (2003) Why do kids eat healthful food? Perceived benefits of and barriers to healthful eating and physical activity among children and adolescents. J Am Diet Assoc 103: 497-501.

51. Siti Sabariah B, Zalilah MS, Norlijah O, Normah H, Maznah I, et al. (2006) Reliability and Validity of the Instrument Used in the HELIC (Healthy Lifestyle in Children) Study of Primary School Children's Nutrition Knowledge, Attitude and Practice. Mal J Nutr 12: 33-44.

52. Pirouznia M (2001) The association between nutrition knowledge and eating behavior in male and female adolescents in the US. Int J Food Sci Nutr 52: 127-32. 53. Dickson-Spillmann M, Siegrist M, Keller C (2011) Development and validation of a short, consumer-oriented nutrition knowledge questionnaire. Appetite 56: $617-20$.

54. Escalante-Guerrero CS, De la Roca-Chiapas JM, Macias-Cervantes MH (2012) Knowledge, attitudes, and behavior concerning nutrition and physical activity in Mexican children. Am J Health Behav 36: 424-31. 
55. Chen S, Soo K, Rahman AA, Van Rostenberghe H, Harith S (2013) Development and Pilot Testing of Nutrition Knowledge, Attitude and Practice Questionnaire in Persons with Disabilities (KAP-nOKU) among Trainers in Rehabilitation Centres, Malaysia. Pak J Nutri 12: 708-14.

56. Golshiri P, Yarmohammadi P, Sarrafzadegan N, Shahrokhi S, Yazadani M, et al. (2012). Developing and validating questionnaires to assess knowledge, attitude, and performance toward obesity among Iranian adults and adolescents: TABASSOM study. ARYA Atherosclerosis Journal 7(Special Issue): S119-24.

57. Johnson F, Wardle J, Griffith J (2002) The Adolescent Food Habit Checklist: reliability and validity of a measure of healthy eating behaviour in adolescents. Eur J Clin Nutr 56: 644-9.

58. Waltz CF, Strickland OL, Lenz ER (2005) Measuring in nursing and health research (3rd edn). Springer, New York, United States.

59. Salvy S, de la Haye K, Bowker JC, Hermans RC (2012) Influence of peers and friends on children's and adolescents' eating and activity behaviors. Physiol Behav 106: 369-78.

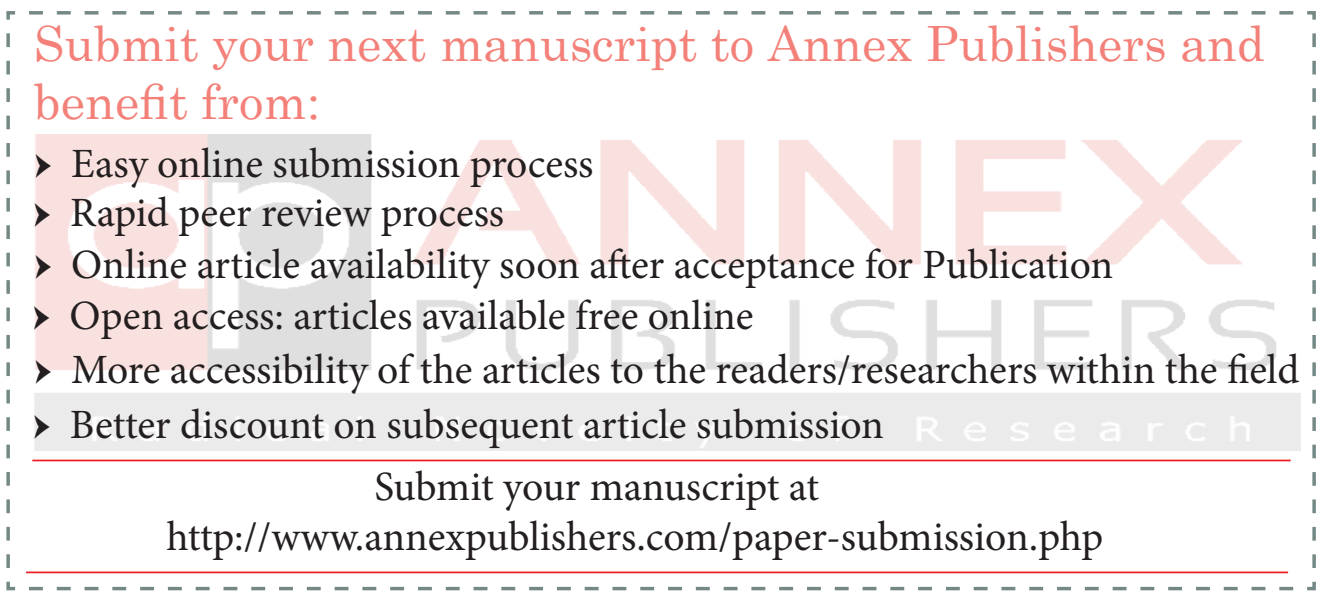

